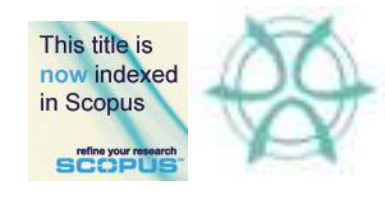

PLANNING MALAYSIA:

Journal of the Malaysian Institute of Planners

SPECIAL ISSUE IV (2016), Page 343 - 352

\title{
A THEORETICAL OVERVIEW OF ROAD HUMP EFFECTS ON TRAFFIC SPEED IN RESIDENTIAL ENVIRONMENTS
}

\author{
Khairun Sarah Radhiah Bachok ${ }^{1}$, Abdul Azeez Kadar Hamsa², Mohd Zin \\ Mohamed $^{3}$ \& Mansor Ibrahim ${ }^{4}$
}

1,2,3,4 Kulliyyah of Architecture \& Environmental Design

INTERNATIONAL ISLAMIC UNIVERSITY MALAYSIA

\begin{abstract}
This paper is part of an ongoing study to analyse the effectiveness of road humps as a traffic calming measure in improving the residential living environment. A review was conducted on various literatures concerning the effects of road humps on vehicle speeds, particularly in residential areas. The major findings from the literatures are that the vehicles' operating speeds are affected by the hump design and spacing in between humps. An incorrect hump profile will also potentially result in passenger discomfort and vehicle damage. Public perceptions also agreed that road humps are effective in reducing vehicle speeds. More studies should link field study results with residents' perceptions particularly in Malaysia, while considering the effect of road geometrics and other devices possibly impacting vehicle speeds along selected roads. Further research also needs to be done to test the effectiveness of current schemes in Malaysian residential areas, as many are on an ad-hoc basis.
\end{abstract}

Keyword: Road humps, Traffic calming, Traffic speed, Living environment, Malaysia

\section{INTRODUCTION}

In Malaysia, the substantial increase in the rate of motorization, with a growth rate averaging $8.16 \%$ for Kuala Lumpur and 6.73\% for Malaysia from 2000 to 2004 has caused serious concerns on the road infrastructure (Kadar Hamsa, 2009). This increasing rate of motorization has subsequently led to concerns on traffic congestion, environmental pollution and road safety. In addition, the rising motorization rate has also resulted in increased road infrastructure. Some of the additional road infrastructure may be constructed in close proximity to residential areas; together with the increase in the number of on-road vehicles, this can raise more concerns on the residential living environment in terms of traffic volume, speed and noise. The occurrence of excessive vehicle speeds is found to be relatively common along local and collector roads with low speed limits (Dinh and Kubota, 2013; Islam et al., 2014), leading to concerns where increased traffic volume and speed have caused the deterioration of living conditions (Litman, 1999, Rahman et al., 2005). These common occurrences of increased vehicle speeds have also been found to cause an increase in accident severity, where the probability of pedestrians receiving fatal injuries when hit by a car is $3.5 \%$ at $15 \mathrm{mph}$ 
Khairun Sarah Radhiah Bachok, Abdul Azeez Kadar Hamsa, Mohd Zin Mohamed \& Mansor Ibrahim A Theoretical Overview of Road Hump Effects on Traffic Speed in Residential Environments

$(24.1 \mathrm{~km} / \mathrm{h}), 37 \%$ at $30 \mathrm{mph}(48 \mathrm{~km} / \mathrm{h})$ and increases to $83 \%$ at $44 \mathrm{mph}(70.8 \mathrm{~km} / \mathrm{h})$ (Limpert, 1994 as cited by Abdul Manan and Hoong, 2009).

As one of the traffic calming measures, road humps have helped to significantly reduce the speed of the moving vehicles especially along residential roads. Due to its largely positive impact in its ability to considerably reduce vehicle speed, its importance has been growing over the years in improving the living environment of the residential areas. However, a prevailing issue in Malaysia is that the Malaysian Traffic Calming Guidelines has not been adhered to in the installation of various existing traffic calming schemes in Malaysian residential areas. This may lead to various issues such as a lack of standardization in dimensions, unsuitable locations, user confusion due to improper construction and no effect on driver behaviour (Abdul Manan and Hoong, 2009). As part of an ongoing research to analyse the effects of road humps in improving the living environment, the objective of this study was to understand the prevailing theories concerning the effects of road humps on traffic speed and also identify the research gaps for the ongoing research to improve upon.

\section{METHODOLOGY}

Being a literature review, the method employed is a desk study identifying the relevant literature and any research gaps that the ongoing research can improve upon. The hump design and spacing were selected as the variables explaining the road hump effects on traffic speed. This is due to Parkhill et al. (2009) and Sundo and Diaz (2011) concluding that the hump spacing is a good variable to explain the maximum speed selection of drivers, thus affecting the effectiveness of a road hump in controlling vehicle speeds. Parkhill et al. (2009) and Antic et al. (2013) also listed the hump profile as another factor affecting the effectiveness of a road hump, with the explanation that an incorrect hump profile would potentially cause passenger discomfort and reduce the effectiveness of a hump in encouraging drivers to slow down. In addition, Daniel (2012) proved that hump width was also a factor by finding that the device operating speed is also affected by hump width to road width ratios. Thus the criteria for selecting the case studies were that they were based on road hump design and spacing, and that the speeds were found to be reduced within the $35 \mathrm{~km} / \mathrm{h}$ limit. The reason for the criteria is that $35 \mathrm{~km} / \mathrm{h}$ is the general speed limit along a traffic-calmed residential road in Malaysian urban areas (Abdul Manan and Hoong, 2009).

\section{TRAFFIC CALMING IN MALAYSIA}

Traffic calming was classified by the Malaysian Highway Planning Unit (HPU) into two categories, which are as below (Abdul Manan and Hoong, 2009):

1) Vertical Measures: Influences drivers' speed through vertical deflections of vehicles passing over the device.

2) Horizontal Measures: Influences drivers' speed through lateral deflections of vehicles navigating the device.

The speed hump is categorized under vertical measures, along with other devices such as transverse bars, speed tables and textured pavements. Vertical measures were stated by the Highway Planning Unit as being more effective in reducing vehicle speeds, in comparison to horizontal measures (Abdul Manan and Hoong, 2009). Thus this study 
is focused on speed humps, as the speed hump is the most commonly found vertical measure in Malaysian residential areas. The Malaysian road hump design specifications, as derived from Malaysian Ministry of Road Works (2012) are as per Table 1 below.

Table 1: Malaysian Road Hump Specifications

\begin{tabular}{|c|c|c|}
\hline Material Used & \multicolumn{2}{|r|}{ Dimension } \\
\hline \multirow{3}{*}{ Asphaltic Premix Wearing Course } & a) & $\begin{array}{l}\text { Flat-Top Hump } \\
\text { Height: } 75 \mathrm{~mm}-100 \mathrm{~mm} \\
\text { Width: } 2.5 \mathrm{~m}-4 \mathrm{~m}\end{array}$ \\
\hline & b) & $\begin{array}{l}\text { Round-Top Hump } \\
\text { Height: } 50 \mathrm{~mm}-100 \mathrm{~mm} \\
\text { Width: } 3.7 \mathrm{~m}-4 \mathrm{~m}\end{array}$ \\
\hline & c) & $\begin{array}{l}\text { Sinusoidal Hump } \\
\text { Height: } 75 \mathrm{~mm}-100 \mathrm{~mm} \\
\text { Width: } 3.8 \mathrm{~m}-4 \mathrm{~m}\end{array}$ \\
\hline
\end{tabular}

\section{CONDITIONS WARRANTING INSTALLATIONS OF ROAD HUMPS}

The Malaysian Ministry of Road Works (2012) defined road humps as a raised area of a pavement, which Berthod (2011) stated causes discomfort due to the vertical displacement created when a vehicle is navigated over the raised area. This influences the drivers to reduce the speed. Hump profiles can be circular, parabolic, sinusoidal or flattopped (Abdul Manan and Hoong, 2009). The difference between road hump and road bump is in the length and slope; a hump's slope is more gradual while its length is greater than the wheelbase of a vehicle (Berthod, 2011).

According to the Malaysian Ministry of Road Works (2012), the conditions that warrant the installation of road humps are as below:

1) Vehicle Speed: Between $30 \mathrm{~km} / \mathrm{h}$ to $60 \mathrm{~km} / \mathrm{h}$

2) Road Hierarchy: District Road, Residential Road, Access Road, Rural Road

3) Road Geometry: 2-way and 2-lane roads with no kerbs.

Nevertheless, there are also conditions for which the installation of road humps would be generally deemed unsuitable. The Malaysian Ministry of Road Works (2012) further explained that the conditions that are deemed unsuitable for speed hump installation are as follows:

1) Water retentive locations

2) Main routes for emergency vehicles

3) Locations at road corners, and

4) Federal and State Roads.

Other studies also noted that it is generally unsuitable to install road humps along bus routes, as humps may cause discomfort to the passengers and delay in the travel times (O' Flaherty, 1997; Parkhill et al., 2009), though this is not mentioned by the Malaysian Highway Planning Unit. A possible explanation is that the existing bus routes penetrate into the residential areas, in which traffic calming devices may still be required for the benefit of residents. 
Khairun Sarah Radhiah Bachok, Abdul Azeez Kadar Hamsa, Mohd Zin Mohamed \& Mansor Ibrahim A Theoretical Overview of Road Hump Effects on Traffic Speed in Residential Environments

\section{EFFECTS OF ROAD HUMP ON TRAFFIC SPEEDS}

Various studies on the effects of road humps have concluded that the road hump is an effective measure in significantly reducing the 85 th percentile of vehicle speeds, with speed reductions ranging from 10 to $16 \mathrm{~km} / \mathrm{h}$ (Appleyard, 1981; Ewing, 1999; Sundo and Diaz, 2011; Huang and Cynecki, 2001; Antic et al., 2013). As stated in the methodology, the review is focused on the effects of road hump design and spacing on reducing the vehicle speeds. The general perception of residents on the effect of road humps is also briefly discussed, in order to further gauge the effectiveness of road humps in a residential area.

\section{Related Literature on Effects of Road Hump Design}

The importance of the hump design in controlling traffic speed was mentioned by Sundo and Diaz (2011) and Antic et al. (2013), who indicated that with an increase in the hump profile's height or severity, the post-entry speeds and speed in between a series of bumps will decrease.

Antic et al. (2013) evaluated the effectiveness of humps $30 \mathrm{~mm}, 50 \mathrm{~mm}$ and 70 $\mathrm{mm}$ height in inverse proportion to the traffic volumes along 3 selected roads, and noted that the speeds reduced with an increase in height. Given that this study made use of humps with similar depths, this means that the slope changes with an increase in height and is thus capable of affecting vehicle speeds. Another notable point made was that despite the significant speed reduction for a hump height of $30 \mathrm{~mm}$, the speeds recorded would result in an $80 \%$ fatality rate in case of a vehicle-pedestrian collision. Hence this is fairly consistent with general literatures that recommend heights of $50-100 \mathrm{~mm}$ (Layfield and Webster, 1998; Bjarnason, 2004; Malaysian Ministry of Road Works, 2012).

In addition, the study by Yaacob and Hamsa (2013) noted that the speed variations were larger in a hump of $60 \mathrm{~mm}$ height as compared to another hump of $80 \mathrm{~mm}$ height. The gentler slope of the $60 \mathrm{~mm}$ hump resulted in more vehicles exceeding the speed limit $30 \mathrm{~m}$ before and after the road hump.

Zainuddin et al. (2014) also found that the hump height was positively correlated with the speed reduction between two measured points, and was also a statistically significant predictor in comparison to hump length and width. This study also developed a regression model to calculate the 85 th percentile speed reduction between two selected points, in which the hump height and length at each point were used as predictors. The predictors can also be rearranged to identify the suitable hump height and length to use in order to achieve the desired speed reduction.

Conversely, Daniel (2012) found that hump width was a significant factor in affecting device operating speeds at road humps. The model in the study suggested that a lower hump width to road width ratio would result in lower speeds. On a road with $12 \mathrm{~m}$ width, a $6 \mathrm{~m}$ wide hump was shown to result in a 10 percent reduction in speed as compared to a hump of $11 \mathrm{~m}$ width. The relation between ratio and reduction was evidenced further when Daniel (2012) commented that the percentage in speed reduction dropped to 2 percent in the case of a $6 \mathrm{~m}$ wide hump constructed over a road with $8 \mathrm{~m}$ width, compared to a $7 \mathrm{~m}$ wide hump. This means that with a larger ratio between hump width and road width, the speed reductions increase. However, a concern with narrower hump widths is that drivers may drive their vehicles along the edges of the humps in order 
to avoid the humps as much as possible. This was one of the negative comments given by respondents in a survey conducted by Cottrell et al. (2006).

On the other hand, the study conducted by Sundo and Diaz (2011) failed to successfully prove the relationship between the hump profile and the driver selection of entry speeds. Thus they stated that the hump height/length ratio was not a good explanatory variable in assessing a driver's speed selection, as there was a wide variation of entry speeds observed. Their conclusion was that driver behaviour is also an important predictor in explaining the speed selection, concurring with Mao and Koorey's (2010) statement that the driving style is a factor to be considered if changes are to be made in the surrounding environment.

\section{Related Literature on Effects of Road Hump Spacing}

In addition to road hump design, the spacing in between road humps also plays a factor in influencing vehicle speeds. Hugh Woo et al. (2010) found that tandem speed humps resulted in significant speed reductions of $1.7-2.17 \mathrm{~km} / \mathrm{h}$ as compared to single humps, in a study that compared the effectiveness of single and tandem speed humps in reducing vehicle speeds along a traffic-calmed road. This concurs with Parkhill et al. (2009) stated that a vehicle's operating speed is also influenced by the spacing of road humps in a particular hump scheme.

The study by Sundo and Diaz (2011), which used the direct-timing procedure to measure vehicle speeds in between two selected humps, found that hump spacing was a good predictor in explaining the maximum speed selection. They also explained that if the spacing between 2 humps were divided into four quarters, the middle 2 quarters or midway between the humps would be designated as the 'Danger Zone' with vehicles reaching peak speeds.

In addition, Yaacob and Hamsa's (2013) study in Taman Setapak, Kuala Lumpur found that with a spacing of $70 \mathrm{~m}$, the 85th percentile speeds recorded $30 \mathrm{~m}$ before and after the second hump were $31.88 \mathrm{~km} / \mathrm{h}$ and $33.20 \mathrm{~km} / \mathrm{h}$ respectively, thus suggesting that shorter hump spacing would be more suitable to maintain the $35 \mathrm{~km} / \mathrm{h}$ speed limit in a Malaysian residential area. However it should be noted that the study was not actively studying the effect of road hump spacing; instead it focused on the individual effect of each hump.

A study conducted by Mao and Koorey (2010) also found that 2 out of the 7 case studies with vertical measures resulted in higher vehicle speeds after installation. A possible explanation given was that the spacing was too far apart, thus allowing drivers to reach maximum speed in between the devices. However this is not always the case. A Federal Highway Administration (1994) study was conducted on two traffic-calmed sections of roads with similar geometric standards, the difference being the traffic volume and road hump spacing. The reduction in the 85 th percentile speeds were $21 \mathrm{~km} / \mathrm{h}$ for Section 1 with $182 \mathrm{~m}$ hump spacing and VPD of 655, and $16 \mathrm{~km} / \mathrm{h}$ for Section 2 with 176 m hump spacing and VPD of 472. It can be seen that even with a closer distance in humps, Section 2 had a lesser effect on vehicle speeds; therefore it may be concluded that the lower traffic volume had also affected the drivers' choice of speed in navigating through the road section. 
Khairun Sarah Radhiah Bachok, Abdul Azeez Kadar Hamsa, Mohd Zin Mohamed \& Mansor Ibrahim A Theoretical Overview of Road Hump Effects on Traffic Speed in Residential Environments

\section{Public Perception on Effectiveness of Road Hump}

Based on the available literature, the public perception on road humps have generally been positive in regards to speed reductions. A study by Kayode (2015) made use of questionnaires targeting a sample of 150 drivers from commercial, private, company and government sectors. The study focused on the perception regarding road bumps; however it found that speed reductions were deemed to be significantly affected by bump type, height, width and spacing. This is concurrent with the literature discussed above on the effects of hump dimension and spacing.

In their study, Cottrell et al. (2006) found that a common positive comment given by the respondents was that the humps reduced traffic speed and volume. This concurred with Du et al. (2001), which studied the perceptions of the residents and travelling public who regularly used the roads and found that both groups agreed on the humps' effectiveness in reducing vehicle speeds. Smith et al. (2002) also reported that after installing temporary road humps, residents agreed that the humps reduced vehicle speeds up to 50 percent. On the other hand, Cottrell et al. (2006) and Du et al. (2001) noted that respondents also complained about drivers speeding aggressively to 'fly' over the humps or driving along the edge of the humps in order to avoid driving over the humps. However this is indicative of variations in driver behavior when navigating over a road hump, and not necessarily an issue regarding the hump design or spacing. Other complaints by the respondents were mostly on the increase in traffic noise levels near the humps (Du et al., 2001; Smith et al., 2002; Cottrell et al., 2006), due to abrupt changes in vehicle speed due to vehicle decelerations and accelerations. Thus it can be generalized that the road hump is effective in addressing the concerns on increased vehicle speeds in residential areas.

\section{Research Gaps from Previous Literature}

The previous researches discussed on the effects of road hump profile and spacing was mostly limited to field tests and simulation studies. More studies should discuss field results together with general public understanding and perceptions on traffic calming, particularly in Malaysia. This is important given the inconsistencies in road hump installations throughout Malaysian urban residential areas, which may cause variations in driver behaviour and thus impact their speed selections. Variations in public opinion regarding hump effectiveness may also occur according to the device characteristics.

In addition, the research conducted by Yaacob and Hamsa (2013) and Zainuddin et al. (2014) did not actively take into account the effect of other road humps or traffic calming devices in the same scheme as those studied, while Sundo and Diaz's (2011) study did not take the effects of the road geometry into consideration.

In regards to the public perceptions briefly discussed above, a limitation of Cottrell et al.'s (2006) study was that the origins of all returned questionnaires were not recorded. Thus it was not possible to analyse the responses according to the neighbourhood or hump characteristics.

\section{DISCUSSION}

It has been widely proven, both through field data and public perception, that road humps are an effective device in controlling the speed of vehicles and ensuring safety for pedestrians and non-motorized road users. Thus a road hump can be installed as a solution for the deterioration of living conditions caused by increased vehicle speeds by causing a 
visual impression that the road was not intended for high-speed or cut-through traffic. Ibrahim et al. (2003) also identified a linear relationship between average vehicle speed and distance from the hump with an R-squared value of 0.91 , indicating that a road hump is significant in reducing the speed of vehicles.

The reviewed literatures have sufficiently proven that the road hump profile and spacing are good predictors in determining the effect of a road hump on the reduction of vehicle speeds. As a result, both predictors can be used in further studies in analysing the effectiveness of road humps.

The standard speed limit along a residential road in Malaysia with road hump installation is $35 \mathrm{~km} / \mathrm{h}$, which drops to $30 \mathrm{~km} / \mathrm{h}$ near a school. According to Table 2 below, the reviewed literature recommend hump heights of $50 \mathrm{~mm}-100 \mathrm{~mm}$ and lengths of approximately $3 \mathrm{~m}-4 \mathrm{~m}$ to achieve vehicle speeds within the $35 \mathrm{~km} / \mathrm{h}$ speed limit in Malaysian urban residential area.

Table 2: Recommended hump profiles according to previous studies

\begin{tabular}{|c|c|c|c|}
\hline Author & Hump Height & Hump Length & Achieved Speed/ Reduction \\
\hline $\begin{array}{l}\text { Mao and Koorey, } \\
2010\end{array}$ & $100 \mathrm{~mm}$ & N/A & $85^{\text {th }}$ percentile $<30 \mathrm{~km} / \mathrm{h}$. \\
\hline Zaidel et al., 1992 & $100 \mathrm{~mm}-120 \mathrm{~mm}$ & $3.7 \mathrm{~m}-4 \mathrm{~m}$ & Travel speed $25-30 \mathrm{~km} / \mathrm{h}$. \\
\hline $\begin{array}{l}\text { Bjarnason, } 2004- \\
\text { citing Watts, } 1973\end{array}$ & $\begin{array}{l}50 \mathrm{~mm}-100 \mathrm{~mm}(\mathrm{R}) \\
100 \mathrm{~mm}-150 \mathrm{~mm}(\mathrm{R}) \\
\end{array}$ & $\begin{array}{l}2.44 \mathrm{~m}(\mathrm{R}) \\
3.66 \mathrm{~m} \mathrm{(R)} \\
\end{array}$ & Crossing speed $25 \mathrm{~km} / \mathrm{h}$. \\
\hline Antic et al., 2013 & $50 \mathrm{~mm}-70 \mathrm{~mm}$ & $0.96 \mathrm{~m}$ & $\begin{array}{l}\text { Reduced } 85^{\text {th }} \text { percentile speeds } \\
\text { ranging from } 10 \mathrm{~km} / \mathrm{h} \text { to } 22 \\
\mathrm{~km} / \mathrm{h} \text {, significant in reducing } \\
\text { risk of collision injuries for } \\
\text { pedestrians. }\end{array}$ \\
\hline $\begin{array}{ll}\text { Layfield } & \text { and } \\
\text { Webster, } 1998\end{array}$ & $75 \mathrm{~mm}(\mathrm{R})$ & N/A & $\begin{array}{l}\text { Reduced } 85^{\text {th }} \text { percentile speeds } \\
\text { between humps by an average } \\
\text { of } 16 \mathrm{~km} / \mathrm{h} \text {. } \\
\text { Compromise to ease movement } \\
\text { of buses and emergency } \\
\text { vehicles. }\end{array}$ \\
\hline Berthod, 2011 & $80 \mathrm{~mm}$ & $4 \mathrm{~m}$ & $\begin{array}{l}85^{\text {th }} \text { percentile speed ranging } \\
\text { between } 30 \mathrm{~km} / \mathrm{h}-35 \mathrm{~km} / \mathrm{h}\end{array}$ \\
\hline $\begin{array}{l}\text { Malaysian Ministry } \\
\text { of Road Works, } \\
2012\end{array}$ & $\begin{array}{l}50 \mathrm{~mm}-100 \mathrm{~mm}(\mathrm{R}) \\
75 \mathrm{~mm}-100 \mathrm{~mm}(\mathrm{~S})\end{array}$ & $\begin{array}{l}3.7 \mathrm{~m}-4 \mathrm{~m}(\mathrm{R}) \\
3.8 \mathrm{~m}-4 \mathrm{~m}(\mathrm{~S})\end{array}$ & $\begin{array}{l}\text { In areas with } 85^{\text {th }} \text { percentile } \\
\text { speed between } 25 \mathrm{~km} / \mathrm{h}-45 \\
\mathrm{~km} / \mathrm{h} \text {, can result in reduction of } \\
\text { speed ranging from } 15 \mathrm{~km} / \mathrm{h}-30 \\
\mathrm{~km} / \mathrm{h} \text {. }\end{array}$ \\
\hline
\end{tabular}

In accordance with Table 3, the literature reviewed recommended a hump spacing of not more than $80 \mathrm{~m}$ to maintain travel speeds within the $35 \mathrm{~km} / \mathrm{h}$ speed limit. However this differs from the Malaysian standard as stated by the Malaysian Ministry of Road Works (2012), which identified $100 \mathrm{~m}$ as the recommended spacing between humps. Nevertheless the Malaysian standard acknowledges that a set of properly spaced humps can significantly reduce travel speeds. The Malaysian Ministry of Road Works (2012) also added that transverse bars can be installed together with humps if greater speed reductions are required, which concurs with Martens et al.'s (1997) statement that 
Khairun Sarah Radhiah Bachok, Abdul Azeez Kadar Hamsa, Mohd Zin Mohamed \& Mansor Ibrahim A Theoretical Overview of Road Hump Effects on Traffic Speed in Residential Environments

transverse road markings or transverse rumble strips can be used to warn drivers of an upcoming hazard and help to reduce speed of the vehicles.

Table 3: Recommended hump spacing according to previous studies

\begin{tabular}{|l|l|l|}
\hline Author & Hump Spacing & Achieved Speed/ Reduction \\
\hline Zaidel et al., 1992 & $\begin{array}{l}40 \mathrm{~m}-60 \mathrm{~m} \text { apart or } \\
\text { away from an } \\
\text { intersection }\end{array}$ & $\begin{array}{l}\text { Travel speed } 25-30 \mathrm{~km} / \mathrm{h} \text {, Hump speed } 15 \\
-25 \mathrm{~km} / \mathrm{h} .\end{array}$ \\
\hline $\begin{array}{l}\text { Mao and Koorey, } \\
2010\end{array}$ & $<60 \mathrm{~m}$ & $85^{\text {th }}$ percentile speeds $<30 \mathrm{~km} / \mathrm{h}$ \\
\hline $\begin{array}{l}\text { Sundo and Diaz, } \\
2001\end{array}$ & $48 \mathrm{~m}-54 \mathrm{~m}(<60 \mathrm{~m})$ & Travel speed $<40 \mathrm{~km} / \mathrm{h}$. \\
\hline $\begin{array}{l}\text { Layfield and } \\
\text { Webster, 1998 }\end{array}$ & $<80 \mathrm{~m}$ & $\begin{array}{l}\text { Mean speeds midway between humps <32 } \\
\mathrm{km} / \mathrm{h}, \text { provided humps are of } 75 \mathrm{~mm} \text { height }\end{array}$ \\
\hline
\end{tabular}

It is also interesting that as explained by Lee et al. (2013), the effectiveness of an existing device installation can also be assessed by using Roess et al.'s (2004) equation. The equation compares the existing spacing with the value derived for $S$. In the case that the existing spacing is less than $S$, it could be assumed that the performance of a road hump would be affected to an extent by any subsequent devices in the traffic calming scheme. Roess et al. (2004) also stated that the equation can be used to determine the minimum distance after passing a traffic calming device. This equation is based on the road's speed limit and minimum driving speed, as below (equation 1).

$$
\frac{\mathrm{v}^{2}-\mathrm{v}_{\mathbf{0}}^{2}}{2 \mathrm{a}}=\mathbf{S}
$$

where,

$V \quad$ : speed limits,

$V_{0} \quad:$ minimum driving speed,

a : acceleration rate (passenger car acceleration rate is $2.286 \mathrm{~m} / \mathrm{s}^{2}$ ), and

$S \quad$ : the resulting minimum spacing between the devices.

However, there is a lack of standardization in the construction of road humps throughout Malaysian urban residential areas (Abdul Manan and Hoong, 2009). Given the importance of the hump profile and spacing in reducing vehicle speeds, the lack of standardization may reduce the effectiveness of road humps as a traffic calming device and cause discomfort to passengers. Thus further studies should be conducted on the effects of existing road hump profiles and spacing to determine their effectiveness in reducing vehicle speeds and improving the liveability of residential areas.

It should also be noted that in addition to the profile and spacing of road humps, some literatures have stated that there are also other factors that need to be considered in analysing the effectiveness of a road hump scheme on vehicle speeds. These factors are namely driver behaviour and the traffic volume along the selected road. The variations observed in driver behaviour upon approaching and accelerating away from the humps have led to inconsistencies in the speeds recorded, and higher traffic volumes will impede drivers from driving at free-flow speeds. The focus on driver behaviour necessitates that the results of a field study be corroborated with the perceptions of residents in the studied 
residential area, in order to further understand the driver behaviour in their speed selections.

\section{CONCLUSION}

The literature review presented in this paper discussed the effectiveness of road humps in reducing the speeds of vehicles along selected roads, particularly in terms of road hump profiles, hump spacing and public perceptions. From the review, it is indisputable that road hump profiles and spacing are important factors to assess road humps along a residential road. However, there are also different factors that may affect the effectiveness of the road hump schemes, such as the daily traffic volume and driver behaviour. The gaps identified from the previous studies are the considerations of road geometry and the effect of other road humps along the selected roads, as well as the analysis of questionnaires according to the neighbourhood and hump characteristics. As the road hump installations in Malaysia have been largely on an ad-hoc basis with no reference to the official guidelines, the analysis of public perceptions according to existing characteristics would be important in Malaysia. Given that the residential living environment is of importance, it would be very significant to understand the residents' perceptions on how the road hump has impacted their environment. Thus any further research conducted in Malaysia should consider public perceptions as an important parameter in determining the effectiveness of road humps, and discuss the perceptions together with the obtained field results based on the existing hump profiles and spacing.

\section{ACKNOWLEDGMENT}

The authors would like to express their gratitude and appreciation to Ministry of Science, Technology and Innovation (MOSTI) for providing the research grant under E-Science fund for this project (project number: 06-01-08-SF0201).

\section{REFERENCES}

Abdul Manan, M.M., Hoong, A.,P., W., (2009). Development and Evaluation of a Traffic Calming Scheme in the Vicinity of Schools in Malaysia: A survey in the Klang Valley. Kajang: MIROS.

Antic, B., Pesic, D., Vujanic, M., Lipovac, K. (2013). The influence of speed bumps heights to the decrease of the vehicle speed- Belgrade Experience. Safety Science. 57: 303-313.

Appleyard, D. (1981). Livable Streets. California: University of California Press.

Berthod, C. (2011). Traffic calming: Speed humps and speed cushions. Paper presented at the 2011 Annual Conference of the Transportation Association of Canada, Edmonton, Alberta.

Bjarnason, S. (2004). Round Top and Flat Top Humps: The Influence of Design on the Effects. Lund Institute of Technology: Sweden.

Cottrell, W.D., Kim, N., Martin, P.T., Perrin Jr, H.J. (2006). Effectiveness of traffic management in Salt Lake City, Utah. Journal of Safety Research, 37: 27-41.

Daniel, B.D. (2012). The influence of width of road humps on operating speed. Paper presented at the Talent Management Symposium 2012, Australia.

Dinh, D.D., Kubota, H. (2013). Profile-speed data-based models to estimate operating speeds for urban residential streets within a $30 \mathrm{~km} / \mathrm{h}$ speed limit. IATSS Research. 36: 115-122.

Du, J., Ivan, J., Garder, P., Aultman-Hall, L. (2003). Public perceptions of traffic-calming device installation. Paper presented at the Institute of Transportation Engineers 2003 Annual Meeting and Exhibit. 
Khairun Sarah Radhiah Bachok, Abdul Azeez Kadar Hamsa, Mohd Zin Mohamed \& Mansor Ibrahim A Theoretical Overview of Road Hump Effects on Traffic Speed in Residential Environments

Ewing, R. (1999). Impacts of traffic calming. TRB Circular E-C019: Urban Street Symposium, I$1 / 1-14$.

Federal Highway Administration. (1994). Traffic calming, auto-restricted zones and other traffic management techniques- Their effects on bicycling and pedestrians (Case study no. 19 publication no. FHWA-PD-93-028). Washington, D.C.: Federal Highway Administration.

Huang, H.F., Cynecki, M.J. (2001). Effects of traffic calming measures on pedestrian and motorist behavior. Transportation Research Record, 1705: 26-31.

Hugh Woo, T., Shih-Ming Ho, Chi-Yuan Lee. (2010). Comparison of single and tandem speed humps in speed reduction. Journal of Society for Transportation and Traffic Studies, 1 (3): 46-53.

Islam, M.T., El-Basyouny, K., Ibrahim, S.E. (2014). The impact of lowered residential speed limits on vehicle speed behaviour. Safety Science, 62: 483-494.

Kadar Hamsa, A.A. (2009). Causes, trends and implications of motorization in Malaysia Proceedings of the Eastern Asia Society for Transportation Studies, Vol. 7.

Kayode, A.A. (2015). Effectiveness of road bumps in relation to speed reduction among vehicle drivers Ilorin Metropolis. Scholarly Journal of Scientific Research and Essay, 4 (4): 61-65.

Layfield, R., Webster, D. (1998). Urban traffic-calming measures: Design, effectiveness, public attitudes and environmental issues (PA 3365/98). Paper presented at the European Transport Conference, United Kingdom.

Lee, G., Joo, S., Oh, C., Choi, K. (2013). An evaluation framework for traffic calming measures in residential areas. Transportation Research Part D, 25: 68-76.

Litman, T. (1999). Traffic calming benefits, costs and equity impacts. Canada: Victoria Transport Policy Institute.

Malaysian Ministry of Road Works. (2012). Kaedah memperlahankan halaju kenderaan: Bonggol jalan. Paper presented at the Seminar Fasiliti Keselamatan Jalan, Kuala Lumpur.

Mao, J., Koorey, G. (2010). Investigating and modelling the effects of traffic calming devices. IPENZ Transportation Group Conference 2010, 1-14.

Martens, M., Comte, S., Kaptein, N. (1997). The effects of road design on speed behaviour: A literature review. Finland: VTT.

O'Flaherty, C.A. (1997). Physical methods of traffic control. In O' Flaherty, C.A. (Ed.), Transport Planning and Traffic Engineering. New Jersey: Pearson Education Inc.

Parkhill, M., Sooklall, R., Bahar, G. (2009). Updated Guidelines for the Design and Application of Speed Humps. Paper presented at the CITE 2007 Conference, Toronto, Ontario, Canada.

Rahman, F., Takemoto A., Sakamoto, K., Kubota, H. (2005). Comparative study of design and planning process of traffic calming devices. Proceedings of the Eastern Asia Society for Transportation Studies. 5, 1322 - 1336.

Roess, R.P., Prassas, E.S., McShane, W.R. (2004). Traffic Engineering (3 ${ }^{\text {rd }}$ ed.) New Jersey, Pearson Education Inc.

Smith, D.J., Knapp, K., Hallmark, S. (2002). Speed impacts of temporary speed humps in small Iowa cities. Ames: Centre for Transportation Research and Education, Iowa State University.

Sundo, B.M., Diaz, C.E.D. (2011). Effect of hump spacing on speed selection of isolated vehicles: The case of exclusive villages in Metro Manila. Proceedings of the Eastern Asia Society for Transportation Studies, 3 (2), 409-423.

Yaacob, N, A., Hamsa, A.A.K. (2013). The effect of road hump in reducing speed of motorcars in a residential area in Kuala Lumpur. Journal of Design and Built Environment, 13, 1-13.

Zaidel, D., Hakkert, A.S., Pistiner, A.H. (1992). The use of road humps for moderating speeds on urban streets. Accident Analysis and Prevention, 24 (1), 45-56.

Zainuddin, N.I., Adnan, M.A., Md Diah, J. (2014). Optimization of speed hump geometric design: Case study on residential streets in Malaysia. ASCE Journal of Transportation Engineering, 140 (3). 